\title{
Game Bahari Menggunakan Algoritma Fisher Yates Suffle Sebagai Pengacak Posisi NPC
}

\author{
Fachrul Kurniawan ${ }^{1)}$, Balqis Kamalia Fikria ${ }^{2)}$ \\ Jurusan Teknik Informatika, Sains dan Teknologi \\ Universitas Islam Negeri (UIN) Maulana Malik Ibrahim Malang \\ ${ }^{1}$ fachrulkurniawan873@gmail.com
}

\begin{abstract}
Abstrak- Latar belakang laut merupakan sebuah hal yang unik dan bisa dikembangkan, karena game dengan latar belakang darat dan udara telah banyak digunakan. Game bahari yang berbentuk 2 dimensi dan dimainkan menggunakan sensor accelerometer adalah pengembangan game berlatar belakang bawah laut. Karakter penyelam sebagai pembersih sampah bawah laut, dimana algoritma fisher yatesshuffle digunakan untuk menentukan posisi dari Non Playable Character(NPC). Dari hasil pengujian implementasi algoritma Fisher Yates Shuffle untuk menentukan posisi NPC pada game Bahari dapat berjalan dengan baik, yaitu dapat digunakan untuk mengacak posisi NPC agar posisinya tidak berulang pada permainan berikutnya. Pengujian dilakukan pada perangkat mobile yang menggunakan platform Android.
\end{abstract}

Kata Kunci: Bahari, Bawah laut,NPC,Accelerometer, Algoritma Fisher Yates Shuffle

\section{PENDAHULUAN}

Indonesia mempunyai kekayaan hayati karena merupakan Negara kepulauan terbesar dunia, dan kekayaan lautnya jika dimaksimal akan bisa menyamai dengan nilai anggaran Negara ini (Rokhmin Dahuri, 2006). Kekayaan alam yang begitu besar ini belum digali dengan maksimal sehingga membuat laut Indonesia bak permata dipandang sebelah. Hal ini berpengaruh juga pada ekosistem laut, karena begitu jarang dipelihara mengakibatkan kerusakan permanen khususnya pada terumbu karang.

Kerusakan alam bawah laut ternyata menyerang pada ikon pariwisat yang sudah terkenal di dunia, yaitu taman wisata Bunaken, di Sulawesi Utara. Keindahan yang begitu mempesona tetapi penuh dengan sampah dibagian dasar lautnya.Menumpuknya sampah dari sejumlah muara sungai daerah Kota Manado mengalir ke Teluk Manado, sehingga menyebabkan penumpukan didasar laut taman Bunaken.

Upaya mengatasi menumpuknya sampah didasar laut taman Bunaken digelarlah kegiatan Reef Clean Up yaitu kegiatan hiburan untuk menikmati keindahan alam bawah laut, sekaligus membersihkan sampah-sampah yang menumpuk didasar laut. Gerakkan di sosialisasikan oleh yayasan terumbu karang Indonesia dengan berbagai kegiatan dan acara.

Reef Clean Up saat ini bisa dilakukan dengan banyak metode dengan beraneka media. Untuk membantu gerakan ini dibuat sebuah game bahari yang mempunyai scenario gerakan pembersihan area bawah laut bunaken. Game merupakan sebuah pilihan baru kampanye bersih bawah laut bunaken, karena game mempunyai sifat dasar menantang (challenging), membuat ketagihan (addicted) dan menyenangkan (fun) (Rahmatsyam Lakoro, 2009)sehingga membuat orang yang bermain game terpengaruh seolah-olah ikut membersihkan lingkungannya.

Berdasarkan hasil penelitian Hanny Haryanto yang berjudul Pendidikan Moraldengan Menggunakan Sistem Reward Dalam Game Imersif, dinyatakan bahwaketika seseorang suka dan gemar bermain game tertentu, maka dapat mempengaruhi tingkah laku dan ber-efek terhadap moral pemainnya sesuai dengan isi dari game itu sendiri.Hal ini bisa dijadikan unsur negative dan positif dari pembuatan sebuah game. Game Bahari dibuat untuk memberi pesan dan gambaran bagaimana gerakan bersih bawah laut dapat dilaksanakan. 


\section{LANDASAN TEORI}

\section{A. Permainan (Game)}

Game adalah media untuk melakukanaktifitas bermain. Aktifitas bermain adalah suatu kegiatanyang bisa memecahkan masalah sehingga menjadi sebuah tantangan tentunya harus mengikuti aturan tertentu.

Game adalah program komputersangat kompleks yang merangsang otak untuk melakukan serangkaian tugas kognitif dan menghasilkan tingkat pemikiran yang lebih tinggi (Beck dan Wade, 2006).

\section{B. Non Playable Character (NPC)}

NPC model berarti obyek dinamis yang tidak menjadi pusat perhatian dan tidak dibawah kontrol pemain, obyek ini bisa membuat keputusan secara mandiri dan beroperasi di wilayah virtual dalam game (Chong-HanKim dkk, 2007)

\section{Algoritma Fisher Yates-Shuffle}

Fisher-Yates Shuffle (yang dinamakan sesuai dengan pengembangnya yaitu Ronald Fisher and Frank Yates) metode ini digunakan untuk merandom posisi atau input (list). Posisi Permutasi dihasilkan oleh metode atau algoritma ini muncul dengan propabilitas yang

Metode Fisher-Yates secara umum adalah sebagai berikut :

1. Deklarasi jumlah elemen dalam array

2. Ambil satu elemen secara acak sesuai dengan jumlah elemen dalam array dan range yang diperbolehkan .

3. Lakukan selama kondisi dari elemen yang masih ada terpenuhi

4. Lalu Ganti elemen yang lama dengan elemen yang sudah di acak jika langkah

ke-2 masih terpenuhi.

Pada versi modern digunakan sekarang, angka yang terpilih tidak dicoret, tetapi posisinya ditukar dengan angka terakhir dari angka yang belum terpilih.

Operasi algoritma fisher yates shuffle dapat diaplikasikan pada game ini dengan ketentuan range adalah jumlah angka yang belum terpilih, roll adalah angka acak yang terpilih, scratch adalah daftar angka yang belum terpilih, dan result adalah hasil permutasi yang akan didapatkan.

\section{Platform Android}

Android adalah sistem operasi untuk ponsel yang berbasis Linux. Android menyediakan platform terbuka bagi para pengembang untuk menciptakan aplikasi mereka sendiri untuk digunakan oleh bermacam peranti bergerak. Android memiliki arsitektur sistem sebagaimana gambar 1.

\section{E. SensorAccelerometer}

Sensor accelerometer adalah sensor yang dapat mengukur percepatan, mendeteksi dan mengukur getaran (vibrasi), dan mengukur percepatan akibat gravitasi (Seifert K dan Camacho, 2007).

Pada smarthphone android, accelerometer dipakai untuk mendeteksiposisi dari handphone apakah dalam mode landscape atau portrait, manfaat utama adalah menu dan aplikasi di smartphone akan menyesuaikan posisi dari smartphone. Manfaat lain biasanya dipakai untuk permainan game, misal game mobil dimana kita cukup memiringkan handphone saat kita mau belok kanan atau kiri. Manfaat lain dipakai untuk mengganti lagu atau mengambil screenshoot hanya dengan menggoyangkan smartphone .

\section{Tabel 1 Operasi Algoritma Fisher Yates Shuffle}

\begin{tabular}{|c|c|c|c|}
\hline Range & Roll & Stratch & Result \\
\hline & & 12345678 & 6 \\
\hline $1-8$ & 6 & 1234587 & 26 \\
\hline $1-7$ & 2 & 173458 & 826 \\
\hline $1-6$ & 6 & 17345 & 1826 \\
\hline $1-5$ & 1 & 5734 & 3186 \\
\hline $1-4$ & 3 & 574 & 431826 \\
\hline $1-3$ & 3 & 57 & 5431826 \\
\hline $1-2$ & 1 & 7 & \\
\hline
\end{tabular}

Permutasi yang didapatkan dari pengerjaan Fisher Yates Shuffle pada Tabel1 diatas adalah 75431826 


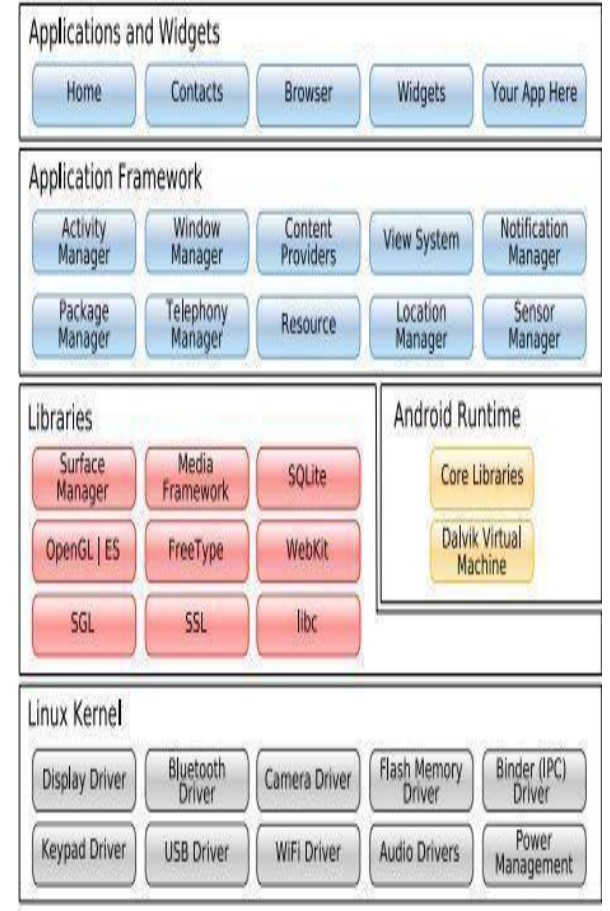

Gambar 1 ArchitectureSistem Android

\section{DESAIN SISTEM}

\section{A. Keterangan Umum Game}

Game merupakan game 2D, dimanauntuk memainkannya pemain dapat menggerakkan gadget/smartphone ke atas atau ke bawah sesuai posisi player yang diinginkan. Dalam game ini pemain harus mengumpulkan sampah dan harus menghindari obstacle.

Sedangkan untuk objek penelitiannya, yaitu posisi NPC tersebut. Pada game ini NPC dibagi dua yaitu NPC sampah dan NPC obstacle. Pemain harus mengumpulkan sampah sebanyakbanyaknya untuk menambah score, serta harus menghindari obstacle agar permainan tidak berakhir (game over).

\section{B. Finite State Machine (FSM) game} Bahari

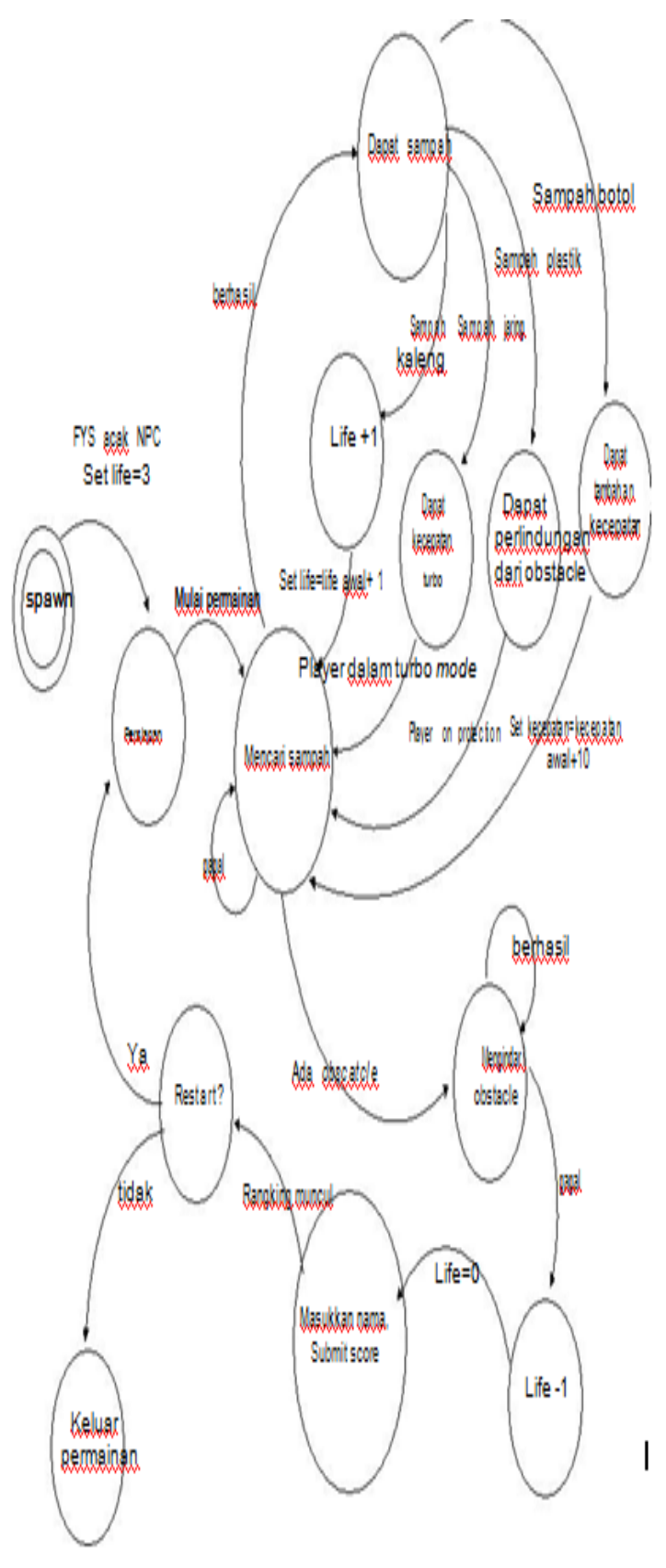




\section{Perancangan Fisher Yates Shuffle pada NPC}

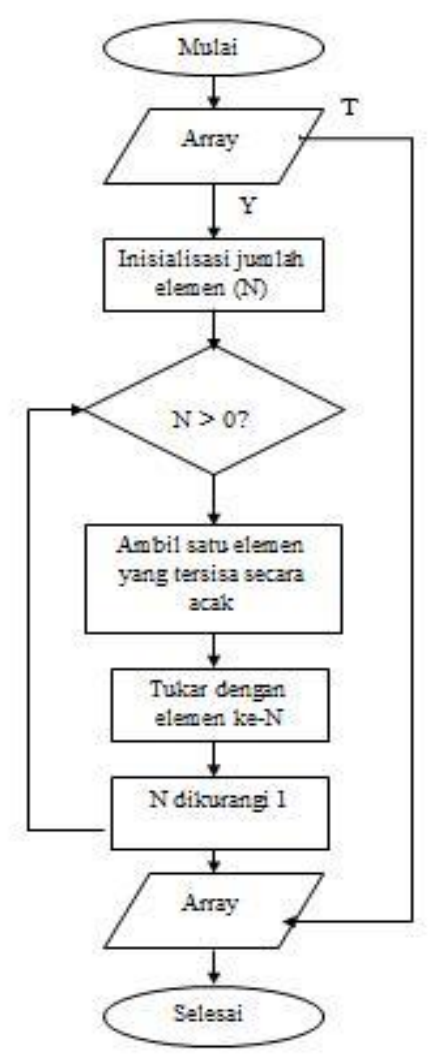

Gambar 2 Flowchart AlgoritmaFisher Yates-Shuffle

\section{HASIL DAN PEMBAHASAN}

\section{A. Implementasi Fisher Yates Shuffle}

Algoritma Fisher Yates Shuffle

diimplementasikan dengan alur sebagai berikut :

1. Melakukan permainan

2. Inisialisasi konten-konten yang ada dalam game

3. Mengacak posisi NPC menggunakan Fisher YatesShuffle

4. Menampilkan NPC

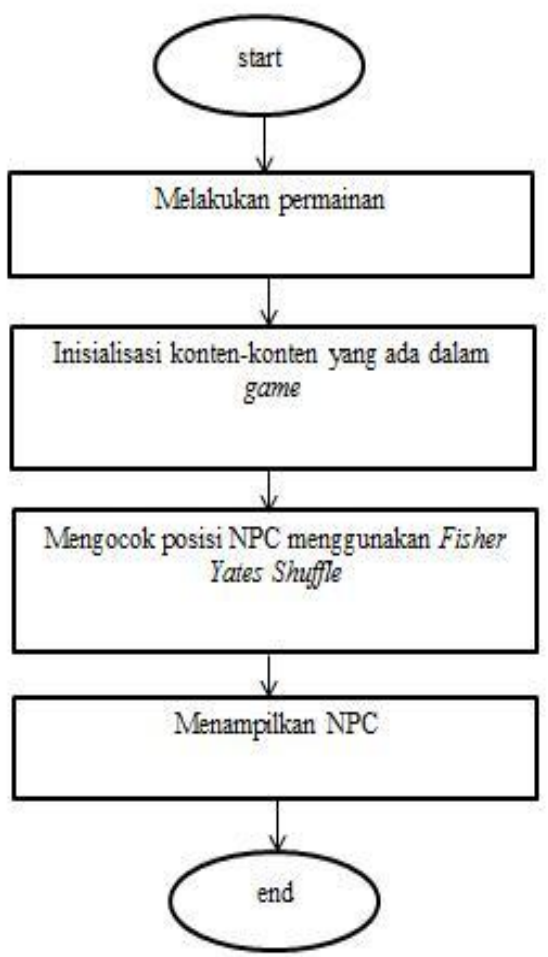

Gambar 3 Blok Diagram Implementasi Fisher Yates Shuffle

Algoritma Fisher Yates Shuffle diimplementasikan menjadi sebuah fungsi Shuffle/kocok dalam sebuah class java yangdiberiFisherYatesnama”." FungsiShuffle tersebut diberiShuffle "nama. “

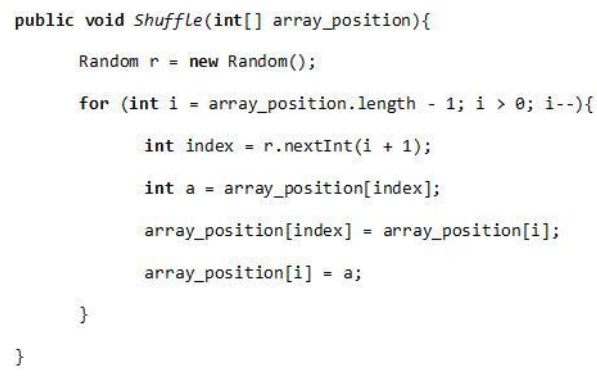




\section{B. Tampilan Game Bahari}

Adapun implementasi dalam game dapat dilihat pada gambar 3.3 dan 3.4

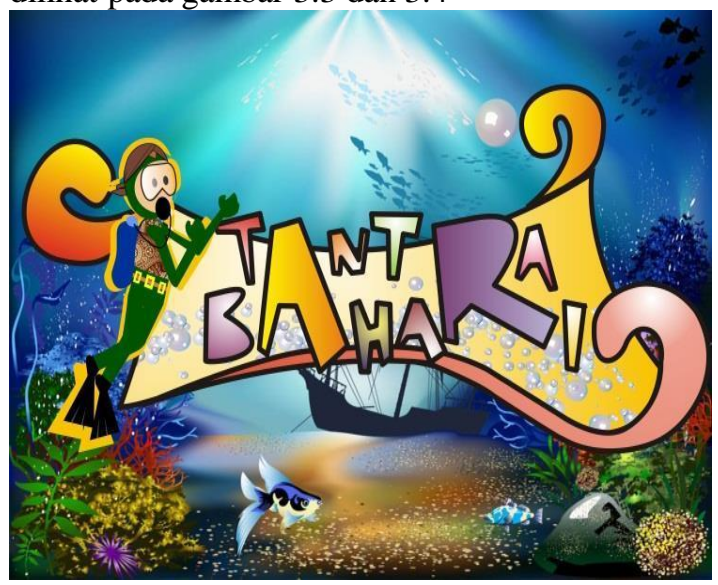

Gambar 4 Tampilan Awal Game

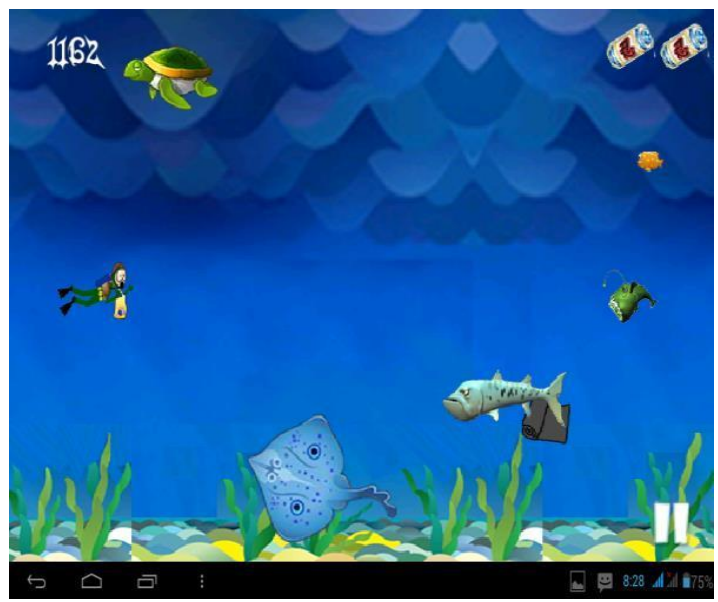

Gambar 5 Tampilan Game Ketika Dimainkan

\section{KESIMPULAN DAN SARAN}

\section{A. Kesimpulan}

Game Baharidalam bermainnya menggunakan accelerometer, dan terdapatpesan moral yakni ajakan untuk membersihkan bawah laut.Algoritma Fisher Yates Shuffledigunakansebagai pengacak array berisi gambar NPC. Dimana permainan array berisi gambar diacak untuk mendapatkan posisi NPC yang tidak berulang sesuai panjang array NPC (N). NPC sampah dengan panjang array 4 $(\mathrm{N}=4)$ atau (array[0..3]) dan NPC obstacle dengan panjang array $8(\mathrm{~N}=8)$ atau [0..7]). Posisi NPC diinisialisasikan dengan nilai koordinat float $\mathrm{x}$ dan float $\mathrm{y}$ dari deklarasi gambar NPC pada layar 720x480.Dari hasil implementasi dan uji coba, algoritma Fisher Yates Shuffle dapat digunakan untuk mengacak posisi NPC pada gameBahari agar posisinya tidak berulang pada permainan berikutnya. Game Bahari ini dipasang pada jenis smartphone android dengan 32versi androidyang berbeda sehingga diketahui pada android OS versi 2.3.5 game tidak berhasil diinstall, dan pada versi OS 4.3 dari device ASUS K012, game dapat diinstall namun sensor accelerometer tidak berfungsi sehingga permainan tidak bisa berjalan dengan baik, selebihnya pada devicesmartphone dengan android OS versi 4.0.4 device Axioo pico 10, versi 4.1.2 dariSamsung GT s5282, versi 4.2.2 dari Oppo R1001, dan dari android OS versi 4.3 Samsung galaxy note 3 game dapat berjalan dengan baik.

\section{B. Saran}

Dalam pembuatan game ini tentu masih banyak kekurangan yang masih perlu dilakukan perbaikan dan pengembangan untuk menjadikan aplikasi ini semakin

bagus dan diminati banyak orang. Oleh karena itu penulis menyarankan beberapa hal untuk bahan pengembangan selanjutnya, diantaranya:

1. Pengembangan game menggunakan algoritma lainnya sehingga bisa membantu pergerakan NPC lebih dinamis lagi.

2. Bisa dikembangkan dalammultiplatformsehingga bisa dimainkan diberbagai system operasi lainnya.

\section{DAFTAR PUSTAKA}

[1] Beck, John C, dan Mitchell Wade. 2006.

[2] Black, Paul E. 2005. "Fisher-Yates Shuffle"Dictionary of Algorithms and Data Structures. National Institute of Standards and Technology.

[3] Durstenfeld, Richard. 1964. "Algorithm235: Random permutation".Communications of the ACM 7 (7): 420. doi:10.1145/364520.364540.

[4] HanKim, Chong dkk. 2006. Verification ofFSM using Attributes 
Definition of NPCs Models. JCSNS InternationalJournal of Computer Science and Network Society.

[5] Haryanto, Hanny. 2010. Pendidikan Moraldengan Menggunakan Sistem Reward Dalam Game Imersif. Semarang:Majalah Ilmiah DIAN.

[6] Henry, Samuel. 2010. Cerdas denganGame: Panduan Praktis Bagi Orangtua dalam Mendampingi Anak Bermain Game. Jakarta: PT. GramediaPustaka Utama.

[7] Ibijola, Ade dan Abejide Olu. 2012, ASimulated Enhancement of FisherYates Algorithm for Shuffling in Virtual Card Games using Domain- Specific Data Structures. International
[8] Journal of Computer Applications, 54:24-28 Diakses tanggal 2 Januari 2014 dari http://www.academia.edu/2985786/ A

[9] Pramudya. Puja. 2007. Game Tebak Kartudengan Windows Multipoint SDK.IlmuKomputer.

[10] Rogers, Rick. 2012. Learning AndroidGame Programming. United States:Pearson Education, Inc.Seifert, K. dan Camacho O. 2007.

[11] Yayasan Terumbu Karang Indonesia. [Online]. http://www.terangi.or.id/ Diakses 11 Januari 2014. 